\title{
Hürthle Cell Carcinoma in a Lingual Thyroid
}

\author{
Jagdeep S. Thakur ${ }^{a}$ Naina Verma ${ }^{a}$ Riya Singh ${ }^{b}$ \\ a Department of Otolaryngology - Head and Neck Surgery, Indira Gandhi Medical College, Shimla, India;

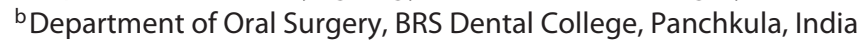

\section{Significance of the Study}

- Lingual thyroid carcinoma is rare and its Hürthle cell variant is even rarer. Lingual thyroid is usually asymptomatic but can present as dysphagia and haemorrhage. A search of the literature in English revealed a single case report of Hürthle cell carcinoma in a lingual thyroid. Here, we report a second case and present the difficulties encountered during management.

\section{Keywords}

Lingual thyroid · Hürthle cell carcinoma - Ectopic thyroid

\section{Abstract}

Objective: To present a case of lingual thyroid Hürthle cell carcinoma (HCC). Clinical Presentation and Intervention: A 37-year-old female presented with dysphagia and recurrent haemorrhage. Histopathology was suggestive of HCC; the tumour was excised by the trans-glossal approach which provided adequate exposure and helped avert external scarring or mandibular osteotomy. Histopathology showed a tumour-positive right lateral resection margin. This prompted referral to nuclear medicine for radio-iodine ablation. Conclusion: Lingual thyroid cases should be followed up closely and fine-needle aspiration biopsy should be considered when in doubt.

(c) 2018 The Author(s) Published by S. Karger AG, Basel

\section{Introduction}

The thyroid gland develops from the foramen caecum which is an endodermal thickening at the junction of the first and second pharyngeal arch and corresponds to the junction of the anterior two-thirds and the posterior onethird of a fully developed tongue. Later, this thyroid tissue descends to the neck in front of the trachea. However, during foetal growth, it may fail to descend or may remain close to its original location at the foramen caecum; in rare cases this may result in the development of a lingual thyroid [1]. The normal thyroid gland in the pretracheal area is absent in about $70 \%$ cases of lingual thyroid $[1,2]$. Other sites of ectopic thyroid include submandibular, thyroglossal duct, intra-tracheal, branchial cyst, lung, mediastinal, heart, ovaries, intestine, pancreas, and adrenal glands [1]. Usually, these ectopic thyroid sites have differentiated thyroid cancer; poorly differentiated cancers are uncommon $[3,4]$. Hürthle cell carcinoma (HCC, oxyphilic or oncocytic carcinoma) is rare in the thyroid

Jagdeep Thakur, MBBS, MS

Department of Otolaryngology - Head and Neck Surgery (ENT)

Indira Gandhi Medical College

Shimla, HP 171001 (India)

E-Mail anujagdeep@yahoo.co.in 


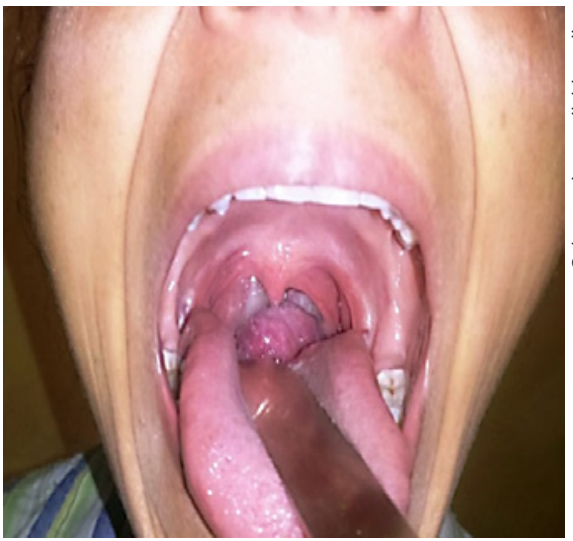

Fig. 1. Clinical photograph of patient showing a large irregular lingual thyroid.
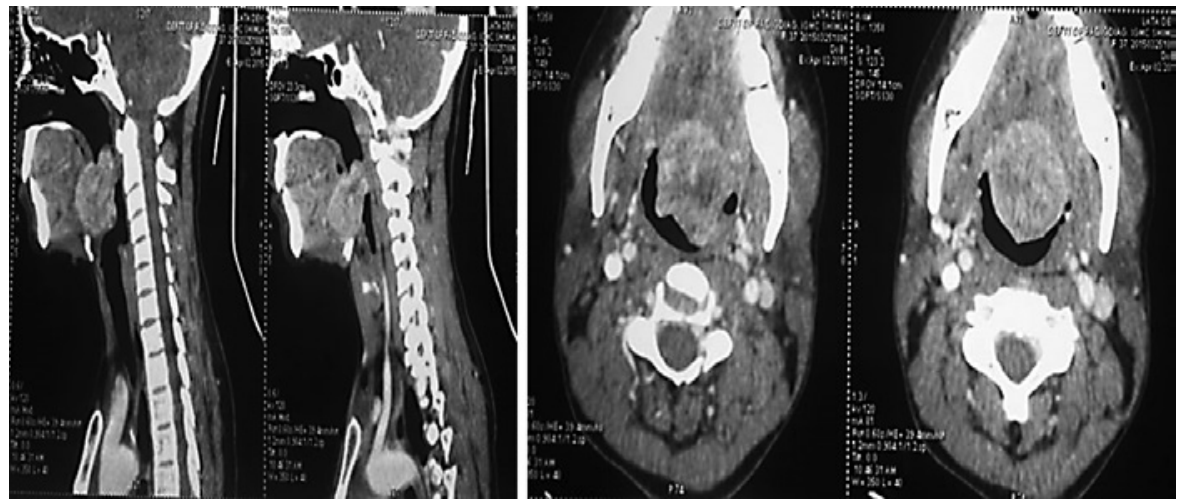

Fig. 2. Contrast-enhanced CT scan of neck showing lingual thyroid.
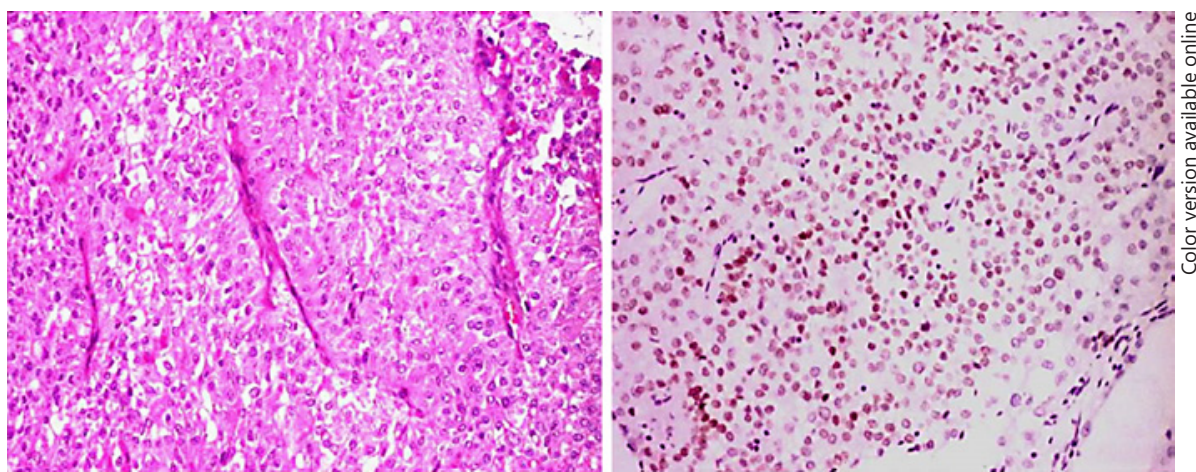

Fig. 3. Histopathological microphotograph suggestive of Hürthle cell carcinoma.

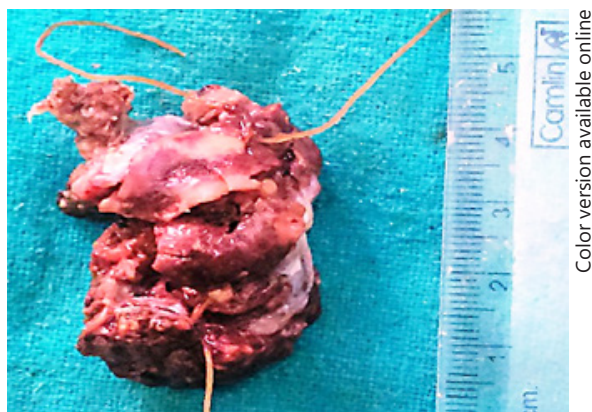

Fig. 4. Excised specimen of the tumour. gland, and its occurrence in ectopic thyroid tissue is even rarer [3-5]. In the English literature, we found a single case report of HCC in a lingual thyroid [4]. We report here a case of HCC in a lingual thyroid, present some difficulties in its management, and review the relevant literature.

\section{Case Report}

A 37-year-old female presented with a swelling in the oropharynx, dysphagia, and a change in the quality of her voice over the previous 5 months. The swelling was painless and progressive in nature. She had a history of hypothyroidism for the previous 10 years and was taking thyroxine $(100 \mu \mathrm{g})$ once daily. There was no other relevant history. Clinical examination revealed a "hot potato" voice (a muffled voice, similar to the voice of a person with a hot potato in their mouth) and a $4 \times 4 \mathrm{~cm}$ tumour with an irregular surface, and firm, non-tender, and appearing to arise from the vallecula (Fig. 1). The tumour was touching the posterior pharyn- geal wall and obscured the laryngeal view. Tongue and neck movements were normal.

The probability of a benign tumour was considered and the patient was subjected to investigations for diagnosis. A CT scan of the neck showed a $4.27 \times 3.79 \times 4.46 \mathrm{~cm}$, lobulated, heterogeneously enhancing lesion in the base of the tongue and an absent thyroid gland in the neck (Fig. 2). These features were suggestive of a lingual thyroid, and this was confirmed by a ${ }^{99 \mathrm{~m}} \mathrm{Tc}$-pertechnetate thyroid scan.

The patient was continued on $100 \mu \mathrm{g}$ oral thyroxine sodium once daily, and surgical intervention was planned in the event of medical failure. Within 1 month, the patient presented with massive bleeding from the oral cavity. On examination, clots were seen to cover the lingual thyroid with no active haemorrhage. She was admitted and external carotid artery ligation or embolization was planned. Surgical excision of the tumour by $\mathrm{CO} /$ diode laser was performed with elective tracheostomy due to the absence of a dominant feeding vessel on CT angiography. However, the tumour bulk restricted retraction of the tongue and resection with laser, which necessitated debulking by electrocautery. Histopathological examination showed follicular/solid tumour cells separated by 


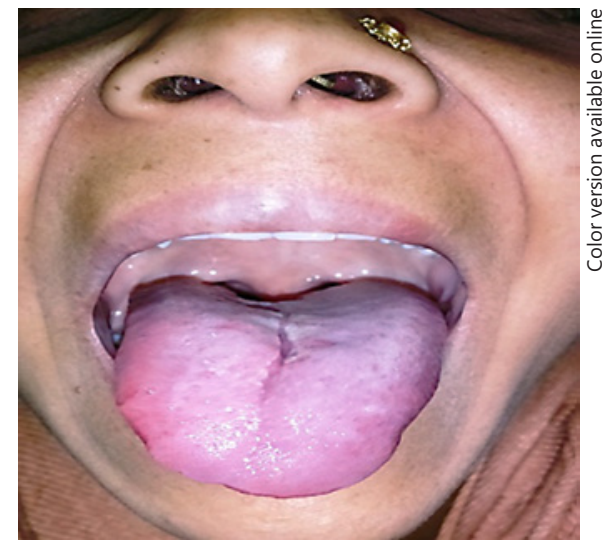

Fig. 5. Follow-up view of the tongue with no morbidity.

thin fibrovascular septa (Fig. 3). The tumour cells had round-tooval pleomorphic vesicular nuclei, prominent nucleoli, and abundant deeply eosinophilic granular cytoplasm with inspissated intraluminal colloid. Capsular and vascular invasion were seen; immunohistochemistry showed the presence of thyroglobulin and thyroid transcription factor- 1 .

Further investigations ruled out regional and distant metastasis. Local wide excision of the tumour was performed by the midline tongue split approach (Fig. 4). Histopathological examination confirmed HCC, and the patient was referred to the Nuclear Medicine Centre for radio-iodine ablation. Radio-iodine tracer uptake was seen in the base of the tongue and in both lungs. The patient received $135 \mathrm{mCi}$ of radio-iodine. She did not have any tongue morbidity (Fig. 5) in the follow-up period of 20 months, after which she has not visited us, to date.

\section{Discussion}

A lingual thyroid usually presents as swelling, dysphagia, or respiratory obstruction in childhood but haemorrhage is rare [1]. Children tend to have stunted growth and hypothyroidism. Ultrasonography shows an absent thyroid gland in the laryngeal area in $70 \%$ of cases [2]. CT scan or MRI is indicated in the case of lingual thyroid presenting with dysphagia or respiratory obstruction, otherwise a thyroid scan shows lingual thyroid. Very few lingual thyroid carcinomas have been reported in the literature; we found only 1 case report of HCC in lingual thyroid $[3,5]$. HCC is a follicular carcinoma variant and constitutes about $3 \%$ of thyroid carcinomas $[6,7]$.

Recent molecular analysis indicated that HCC is an entity that is distinct from differentiated thyroid cancers $[6,8]$. HCC is characterized by oncocytes, a high nucleusto-cytoplasm ratio, and eosinophilic granular cytoplasm due to the increased number of cytoplasmic mitochondria [4]. Hürthle cell thyroid carcinoma is found predominantly in women and older individuals. It has a poor prognosis, and hence an aggressive management strategy is recommended. HCC usually present with cervical lymphadenopathy, but regional, distant, and unusual sites have also been reported [4]. Fine-needle biopsy cannot differentiate Hürthle cell adenoma (a follicular carcinoma variant) from cancer, as the vascular and capsular invasions are prerequisites for labelling carcinoma. Immunohistochemistry and tissue-quantitative fluorescence in situ hybridization have revolutionized lab diagnosis [8]. Ki-67 (a cellular proliferation marker) and GRIM-19 (a protein involved in cell proliferation and apoptosis) are important cytological markers for diagnosing HCC. PIK3CA-Akt-m-TOR and Wnt/ $\beta$-catenin pathways have helped differentiate Hürthle cell adenoma and carcinoma [8]. Few studies have evaluated ultrasonographic features such as size and echogenicity to differentiate Hürthle cell neoplasm, but none has been conclusive as these are standard features of thyroid cancer $[7,9]$.

Treatment of lingual thyroid depends upon the clinical presentation. Asymptomatic patients require thyroxine supplementation to manage hypothyroidism and mild dysphagia. Surgical intervention is required in dysphagia, respiratory obstruction, haemorrhage, and, rarely, malignancy. Surgical excision can be performed trans-orally, or by means of a trans-mandibular or trans-hyoid approach, depending upon the size and location of the thyroid gland. Robotic surgery has recently emerged as an excellent substitute for the latter approaches, but the high cost is a drawback of this technique. We excised the HCC using the trans-glossal approach, as this provided adequate exposure and appeared superior to trans-mandibular and lateral pharyngotomy by averting external scarring and mandibular osteotomy. The management of the thyroid gland in cases of ectopic thyroid malignancy was once controversial, but is now managed based on risk stratification, and total thyroidectomy is indicated for high-risk cases. All cases of HCC should be subjected to a radioiodine scan to assess iodine avidity, and then undergo ablation accordingly. Chemotherapy and external beam radiotherapy are used in refractory or recurrent cases.

\section{Conclusion}

Although the malignant potential of an ectopic thyroid is controversial, this second case report of HCC in a lingual thyroid raises an important question regarding con- 
servative management of the lingual thyroid. In our opinion, lingual thyroid cases should be followed up closely by CT scan and subjected to fine-needle aspiration biopsy to exclude carcinoma whenever clinical features alter. However, fine-needle aspiration is limited in terms of its in- ability to distinguish follicular adenoma or carcinoma (including its variants) and is also known to cause infarct in HCC, and so should be performed only after radiological and nuclear investigations.

\section{References}

1 Bull PD: Branchial arch fistulae, thyroglossal duct anomalies and lymphangioma; in Gleeson M, Browning GG, Burton MJ, et al (eds): Scott Brown's Otorhinolaryngology, Head and Neck Surgery, vol 1, ed 7. London, Hodder Arnold, 2008, pp 1264-1271.

2 Guerra G, Cinelli M, Mesolella M, Tafuri D, Rocca A, Amato B, et al: Morphological, diagnostic and surgical features of ectopic thyroid gland: a review of literature. Int J Surg 2014; 12:S3-S11.

3 Sturniolo G, Violi MA, Galletti B, Baldari S, Campennì A, Vermiglio F, et al: Differentiated thyroid carcinoma in lingual thyroid. Endocrine 2016;51:189-198.
4 Monaco M, Chiappetta G, Aiello C, Federico A, Sepe R, Russo D, et al: CBX7 expression in oncocytic thyroid neoplastic lesions (Hürthle cell adenomas and carcinomas). Eur Thyroid J 2014;3:211-216.

5 Seoane JM, Cameselle-Teijeiro J, Romero MA: Poorly differentiated oxyphilic (Hürthle cell) carcinoma arising in lingual thyroid: a case report and review of the literature. Endocr Pathol 2002;13:353-360.

6 Sheth S: Role of ultrasonography in thyroid disease. Otolaryngol Clin North Am 2010;43: 239-256.
7 Lee KH, Shin JH, Ko ES, Hahn SY, Kim JS, Kim JH, et al: Predictive factors of malignancy in patients with cytologically suspicious for Hürthle cell neoplasm of thyroid nodules. Int J Surg 2013;11:898-902.

8 Donatini G, Beaulieu A, Castagnet $M$, Kraimps JL, Levillain P, Fromont G: Thyroid Hürthle cell tumors: research of potential markers of malignancy. J Endocrinol Invest 2016;39:153-158.

9 Parikh PP, Allan BJ, Lew JI: Surgeon-performed ultrasound predictors of malignancy in patients with Hürthle cell neoplasms of the thyroid. J Surg Res 2013;184:247-252. 